\section{Andes observatories belatedly take root}

Roland Pease

M any astronomers regard Chile as the best place on Earth for astronomy. A stroll at night outside the dome at the Cerro Tololo Inter-American Observatory (CTIO) near La Serena in northern Chile reveals why. The sky is crystal clear, and so still that stable images of stars are a near certainty. Then there is the weather. During the summer months, from January to March, cloudless skies are almost guaranteed - a priceless asset for a profession that is at the mercy of the elements.

Little wonder, then, that the world of astronomy has beaten a path to Chile's door: up to 800 foreign astronomers visit each year. Besides the CTIO, with its seven telescopes, there are the telescopes at Las Campanas, run by the Carnegie Institution of Washington, and the European Southern Observatory (ESO) at La Silla, on the southern edge of the Atacama desert. And more are being built.

The three main observatories have been running since the early 1960s, and Chile had a history of involvement in astronomy long before then. A national observatory was established at Cerro Calán on the outskirts of Santiago in 1852, fulfilling the usual maritime and timekeeping functions of observatories at that time.

Foreign involvement goes back a long way too: US astronomers came to Santiago as early as 1847 and a southern-skies outpost was established by California's Lick Observatory in 1902. For many years, this was the largest telescope in the Southern Hemisphere. It was inherited by the University of Chile when the Californians left, but closed in the 1940s.

The rebirth of astronomy at the end of the 1950 s was very much the result of efforts by local astronomers, although the money and technology came from abroad. It was the director of Chile's national observatory, Federico Rutland, who, learning of US interest in southern astronomy, persuaded Gerard Kuiper from the University of Chicago to survey the coastal mountains of northern Chile for suitable sites for a new observatory.

The CTIO was the outcome of that search: "one of the best observatories in the world" says Nick Suntzeff, a staff astronomer there. Its large four-metre telescope made a key contribution to the recent discovery of accelerating expansion over the history of the Universe (Garnovich et al. Astrophys. J. 493, L53-L57; 1998).

From the outset, Chile won access to 10 per cent of the available time at CTIO for its own astronomers, although access at ESO has been agreed only from this year.

\section{University held "monopoly"}

Hernán Quintana, head of astronomy at the Catholic University in Santiago, says that lack of access held back Chilean astronomy — but claims that an even more significant problem was the effective monopoly held on the discipline by the University of Chile, the country's main public university, after it absorbed the national observatory in 1964.

The Catholic University is now challenging that monopoly, and Quintana believes that a greater intake of undergraduate and graduate students in astronomy will enable the country to develop excellence in the discipline. (In common with most senior Chilean scientists in all disciplines, Quintana himself was trained outside Chile.)

But José Maza, head of astronomy at the University of Chile, counters that training more students will not necessarily lead to better science. He remains unconvinced that funded positions will become available for many more astronomers than the 25 or so which Chile has at the moment.

Quintana also accuses the government of indifference. Chile's involvement in the new Gemini telescopes - giant eight-metre instruments being placed in Hawaii and near La Serena - was nearly forfeited by the treasury's failure to pay the US $\$ 9$ million subscription until almost the day of the

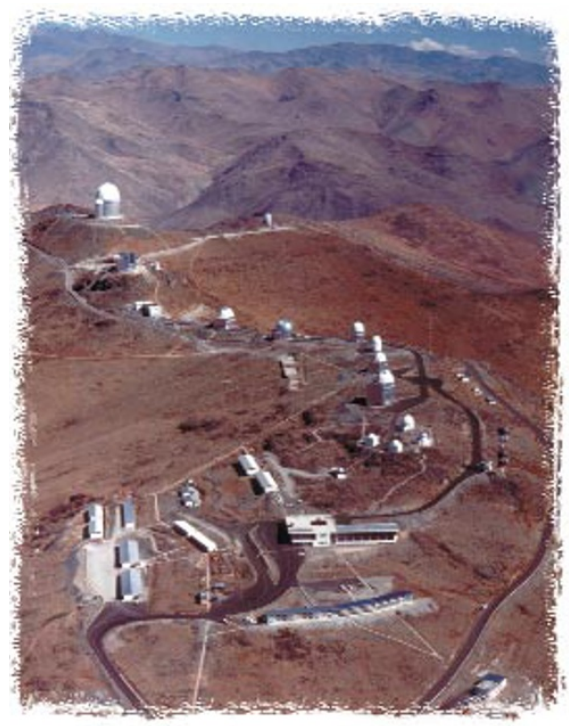

The European Southern Observatory offered no time to Chilean astronomers until this year.

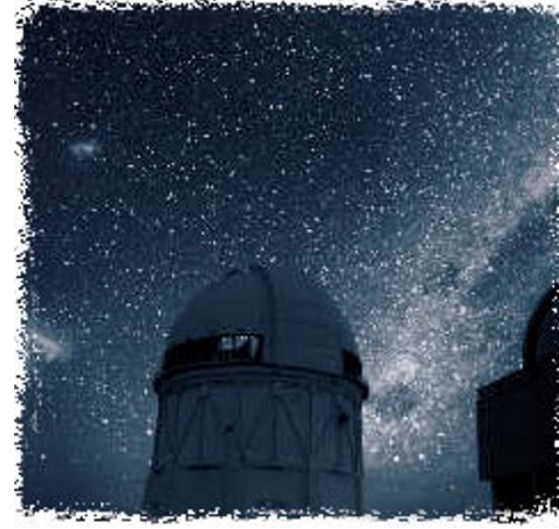

The CTIO has helped enable breakthroughs in our understanding of the Universe.

deadline, in 1997, he says. Astronomers were not involved in the negotiations, and nor was CONICYT, the main science funding agency.

Help for Chilean astronomy is coming from outside. The Andes Foundation, a trust fund based in New York that puts seed money into Brazil, Argentina and Chile, regards astronomy as the key Chilean science. And the Catholic University and the University of Chile have established links with Princeton and Yale universities, respectively, to collaborate on research and graduate training.

The project manager for Gemini's southern site, Oscar Riveros, who is also CONICYT's coordinator for astronomy, sees it as an opportunity to build up an indigenous astronomy infrastructure. The project's communications, for example, are being developed by a consortium of Chilean universities and the telephone company CTC. Four Chilean engineers have spent the past year working at Gemini's northern site, in Hawaii, and another will be visiting Britain to learn about the optical-coating paint for Gemini South's mirror.

The tables have turned since the days when Chile made no demands for scientific involvement in the ESO. If anything, Riveros says, it has been too successful in negotiating with its guests. Chile now has access to 350-400 nights of observing time a year on its soil - enough to keep over a hundred astronomers busy. And if Riveros thinks it is a challenge to find that number, Quintana is more optimistic. "Because of the big observatories in Chile, we're coming much more into the public eye," he says. "People realize that there are going to be jobs in astronomy."

The result is some enthusiasm for astronomy among young Chileans. Chile has a rigorous national schools testing system, in which every high school graduate receives a score of up to 815 points. The best student in the country last year, according to Francisco Claro, dean of research at the Catholic University, scored 814 points, and has chosen to join the university's new undergraduate astronomy programme. 